\title{
Pulmonary hypertension: an emerging risk in hemoglobin disorders
}

\author{
D. Farmakis, A. Aessopos \\ First Dept. of Internal Medicine, University of Athens Medical School, Laiko Hospital, Athens, \\ Greece
}

\begin{abstract}
Pulmonary hypertension (PH) is one of the main cardiovascular complications in haemoglobinopathies and is considerably implicated in patients' morbidity and mortality. In thalassemia intermedia, PH is found in about $60 \%$ of traditionally managed patients and represents the main cause of heart failure. In sickle cell anemia, PH is encountered in one third of patients and has been found to be a strong and independent predictor of mortality, while in sickle thalassemia, $\mathrm{PH}$ is generally less frequent and severe. The pathophysiology of $\mathrm{PH}$ in haemoglobinopathies is multifactorial and several mechanisms seem to be implicated, including a complex vasculopathy, hypercoagulability and elastic tissue defects, all associated with chronic hemolysis, high output state due to chronic anemia, as well as left heart dysfunction, pulmonary disorders and thromboembolic complications. Echocardiography is the most useful tool for patients' screening on a regular basis, while the diagnosis of $\mathrm{PH}$ should always be confirmed by right cardiac catheterization. The proper management of the disease itself with haematological modalities such as blood transfusions combined with iron chelation or hydroxyurea, is the most effective approach for the prevention and treatment of haemoglobinopathy-associated $\mathrm{PH}$. Antithrombotic agents should also be considered while the value of novel agents used in the treatment of pulmonary arterial hypertension, including endothelin antagonists or phosphodiesterase- 5 inhibitors, is not yet established in patients with haemoglobinopathies.
\end{abstract} Correspondence: D. Farmakis, First Dept. of Internal Medicine, University of
Athens Medical School, Laiko Hospital, Athens, Greece.

Key words: pulmonary hypertension; pulmonary arterial hypertension; hemoglobinopathies; thalassemia; sickle cell disease.

(C) Copyright D. Farmakis and A. Aessopos, 2011

Licensee PAGEPress, Italy

Thalassemia Reports 2011; 1(s2):e18

doi:10.4081/thal.2011.s2.e18

This article is distributed under the terms of the Creative Commons Attribution Noncommercial License (by-nc 3.0) which permits any noncommercial use, distribution, and reproduction in any medium, provided the original author(s) and source are credited.

Parts of this work were presented at the "12th International Conference on Thalassemia and Hemoglobinopathies", Antalya (Turkey), 11-14 May 2011.

\section{Introduction}

The haemoglobinopathies constitute a heterogeneous group of hereditary haemoglobin disorders, characterized either by reduced (thalassemias) or defective (sickle cell disease) globin chain synthesis that results in chronic haemolytic anemia. They represent the most common monogenetic disorders in humans and although traditionally confined to specific geographical areas and populations (the Mediterranean Basin, Middle and Far East in the case of $\beta$-thalassemia, Sub-Saharan Africa and African-Americans in the case of sickle cell disease), they have currently expanded to a global distribution due to the immigration of those populations to the Western World. ${ }^{1,2}$ Although their clinical severity is variable, the hemoglobinopathies are generally demanding conditions, particularly in the homozygous state, characterized by reduced survival, multi-organ complications, frequent hospitalizations and need for life-long management. Thus, they represent a significant medical and socio-economical problem.

Cardiovascular complications are among the leading causes of mortality and morbidity in haemoglobinopathies. ${ }^{2}$ The spectrum of cardiovascular manifestations in those patients is wide and pulmonary hypertension (PH) holds a prominent place. ${ }^{1}$ Actually, $\mathrm{PH}$ has been recognized as the most striking cardiovascular finding and the main cause of heart failure in patients with thalassemia intermedia, being present in approximately $60 \%$ of cases studied. ${ }^{3,4}$ On the other hand, $\mathrm{PH}$ is a major determinant of survival in patients with sickle-cell anemia, in whom a prevalence of $20-30 \%$ has been noted, ${ }^{5,6}$ while it has also been observed in patients with sickle-cell thalassemia, although with a lower frequency and a lesser severity compared to sickle-cell anemia. ${ }^{7}$ Moreover, an increased prevalence of $\mathrm{PH}$ has been reported by earlier studies in poorly treated thalassemia major patients, ${ }^{8,} 9$ although recent trials in regularly treated cohorts did not confirmed the finding in this particular population. , $^{10}$

Besides the haemoglobinopathies, it has been observed that other chronic haemolytic conditions, such as hereditary spherocytosis and microangiopathic hemolytic anemia, also have an increased occurrence of $\mathrm{PH} .{ }^{11}$ To reflect this correlation, $\mathrm{PH}$ associated with chronic hemolytic anemia has been included as a subcategory of pulmonary arterial hypertension (PAH) in the recent Dana Point classification (group 1). ${ }^{12}$

Hemolysis seems to hold a key role in the development of PH in patients with haemoglobinopathies and other chronic hemolytic conditions. It has been shown that chronic hemolysis leads to nitric oxide (NO) depletion due to NO scavenging, arginine catabolism and endogenous NO synthesis inhibition, as well as due to enhanced platelet activation and increased enothelin-1 release. ${ }^{6,} 13$ All those events lead in turn to a vasculopathy, characterized by endothelial dysfunction, increased vascular tone, inflammation, hypercoagulability and finally vascular remodeling and destruction of pulmonary vasculature. 6,14 
Hemolysis and the resulting oxidative tissue damage have also been suggested that they lead to the development of a particular acquired elastic tissue defect that resembles hereditary pseudoxanthoma elasticum, which is encountered with a surprisingly high frequency in patients with thalassemia and sickle-cell disease. ${ }^{15}$ Actually, it has been shown that $85 \%$ of patients with thalassemia intermedia older than 30 years have at least one of the typical manifestations of the defect namely skin lesions, ocular angioid streaks and arterial degeneration, ${ }^{16}$ while subclinical pathology findings were found in $96 \%$ of young patients with thalassemia major and other hemolytic conditions. ${ }^{17}$ This defect has been related to a number of vascular and other complications, including pulmonary arterial lesions, ${ }^{18,} 19$ hence providing a structural component to the aforementioned hemolysis-related vasculopathy. ${ }^{14}$

A hypercoagulable state is another notable finding in haemoglobinopathies ${ }^{20}$ Hypercoagulability results from a spectrum of abnormalities including the native erythrocyte precoagulant surface, the frequently performed splenectomy, some coexistent genetic coagulation defects and the previously mentioned endothelial dysfunction and vasculopathy. ${ }^{21}$ Several thromboembolic complications have been reported in haemoglobinopathy patients, especially in those with thalassemia intermedia and splenectomy or sickle cell disease, including pulmonary embolism and in situ thrombosis. ${ }^{21,22}$

Besides hemolysis-related vasculopathy and hypercoagulability, further lung injury in patients with hemoglobinopathies results from additional disorders such as the vaso-occlusive crises and the acute chest syndrome in sickle-cell disease, the iron overload in transfusiondependent cases, the recurrent respiratory track infections and the aforementioned elastic tissue defect. ${ }^{6,21}$

In addition to pulmonary arterial disorders, lung disease and thromboembolic events (groups 1, 3 and 4 of the Dana Point classification), patients with haemoglobinopathies also have an increased occurrence of left-sided heart disease and it is well know that up to $60 \%$ of cases with severe systolic and up to $70 \%$ of those with isolated diastolic left ventricular (LV) dysfunction develop some degree of PH (group 2 in the Dana Point classification). ${ }^{12}$ Actually, right cardiac catheterization in 26 sickle-cell anemia patients with PH showed that $54 \%$ of them had PAT, while the rest $46 \%$ had pulmonary venous hypertension..$^{23}$ Left ventricular dilatation and eccentric hypertrophy is common in all haemoglobinopathy patients. ${ }^{3,4,7,10}$ Systolic LV dysfunction is the typical finding in transfusion-dependent thalassemia major patients, while restrictive $\mathrm{LV}$ filling is also encountered in these cases. ${ }^{2,}$, 10 Interestingly, even in a cohort of optimally treated thalassemia major patients, $7 \%$ of cases had impaired systolic function and $38 \%$ had restrictive $\mathrm{LV}$ filling. ${ }^{10}$ Left-sided valvular disease has also been encountered with a higher percentage with respect to normal individuals of similar age, especially in the form of mitral regurgitation and prolapse. $3,7,24$ The main mechanisms involved in the pathogenesis of left heart disease in those patients include high output state, iron overload, myocarditis and other immuno-genetical factors and the aforementioned elastic tissue defect. $2,3,4,7,10,15,21,25$

Chronic anemia induces a compensatory high output state and volume overload. This is particularly evident in hemoglobinopathies, in which high cardiac output is related to the chronic tissue hypoxia that results from the low total hemoglobin levels and the increased levels of hemoglobin $\mathrm{F}$, the compensatory bone marrow expansion, splenomegaly and the coexistent hepatic injury. ${ }^{21}$ It has been shown that even optimally transfused patients with thalassemia major have increased levels of cardiac output. ${ }^{4,10}$ High output state damages pulmonary vasculature and hence contributes to the pathogenesis of $\mathrm{PH},{ }^{21,26}$ while at the same time it may also lead to the overestimation of pulmonary artery pressure for a given level of pulmonary vascular resistance, particularly when assessment relies only on echocardiography. ${ }^{11}$ Finally, hepatic injury, resulting from iron overload, blood borne infections and bone marrow expansion, may lead to cirrhosis and thus development of porto-pulmonary hypertension., 21

The combined effects of the aforementioned factors increase pulmonary resistance and cardiac output and thus lead to the development of PH (Figure 1). ${ }^{1,26}$ Hence, it becomes obvious that $\mathrm{PH}$ associated with hemoglobinopathies is a complex condition with multiple pathogenic mechanisms that cover practically all categories of PH. Therefore, we think that this condition should better be included in the group of conditions with unclear or multifactorial pathophysiology (group 5) in a future update of the classification. Actually, other hematological disorders such as myeloproliferative diseases have also been included in this category. ${ }^{12}$

Besides the complexity of the disorder, another reason to focus on hemoglobinopathy-associated $\mathrm{PH}$ is the bulk of a problem that is frequently overlooked and is usually unknown to the general cardiovascular physician. As stated, the hemoglobinopathies are the most common monogenetic disorder in humans, while it has been postulated that hemoglobinopathies and particularly sickle cell disease along with HIV infection might be the most common causes of $\mathrm{PH}$ worldwide considering the high prevalence of $\mathrm{PH}$ in those populations. ${ }^{27}$ The third and most essential reason is the fact that there are several disease-specific and effective measures that can be taken for the treatment and mainly for the prevention of $\mathrm{PH}$ in those patients.

Anticoagulation and novel drug categories, including phosphodiesterase (PDE)-5 inhibitors, endothelin receptor antagonists and prostacyclin analogues have been introduced for the management of $\mathrm{PAH}$. Some of the novel agents have also been tested in patients with hemoglobinopathies. Small clinical trials have shown some promising preliminary results with PDE-5 inhibitors and endothelin antagonists. ${ }^{28-32}$ However, a randomized trial of sildenafil in patients with sickle cell disease sponsored by the American National Institute of Health was halted before completion due to the increased occurrence of painful crises in the sildenafil arm. Until further studies clarify the effectiveness and safety of the novel agents in haemoglobinopathies, the management of those patients should focus on the disease-specific therapeutic targets that derive by the diverse pathogenic mechanisms involved. Proper transfusion therapy holds a central role as it restores tissue oxygen delivery and suppresses the synthesis of native, defective erythrocytes, hence preventing hemolysis, hypercoagulability, tissue hypoxia and volume overload. ${ }^{1,26}$ The concomitant iron chelation therapy prevents iron accumulation and the resulting oxidative tissue

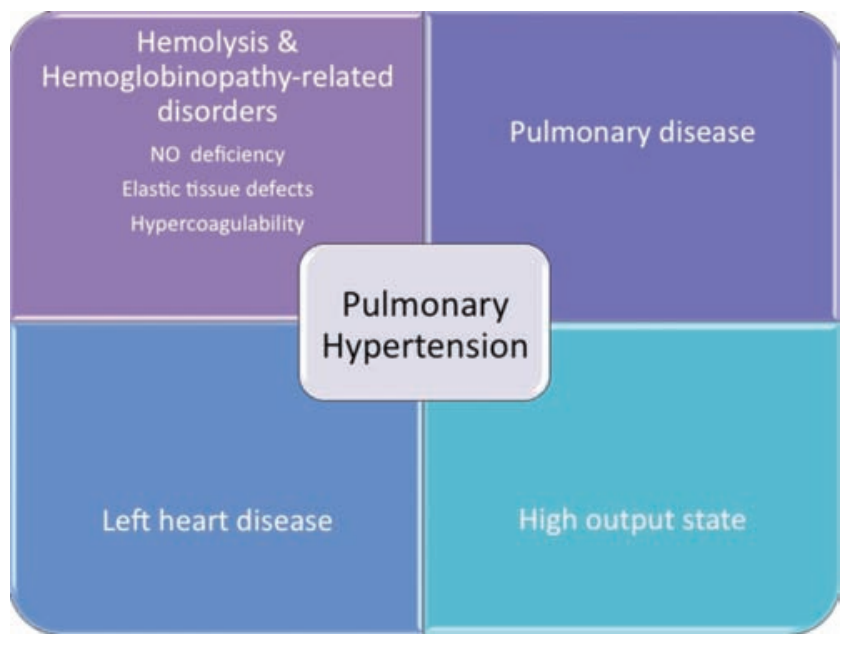

Figure 1. Main pathogenetic mechanisms of pulmonary hypertension in hemoglobinopathies. 
damage, including ventricular dysfunction and lung injury. 1,26 Hydroxyurea modifies the defective hemoglobin synthesis and reduces thrombocytosis, hence preventing hemolysis and hypercoagulability. Actually, in a very recent study of 584 patients with thalassemia intermedia, all main haematological therapeutic modalities, including transfusions, iron chelation and hydroxyurea, proved protective against PH. ${ }^{33}$ Smaller studies or case reports have also shown the beneficial effects of blood transfusions or hydroxyurea on $\mathrm{PH}^{34,35}$

In conclusion, $\mathrm{PH}$ associated with hemoglobinopathies represents an important clinical entity that may be preventable or at least rationally managed if its multifactorial pathophysiology and the resulting essential therapeutic implications are not overlooked.

\section{References}

1. Farmakis D, Aessopos A. Pulmonary hypertension associated with hemoglobinopathies: Prevalent but yet overlooked. Circulation 2011;123:1227-32.

2. Kremastinos DT, Farmakis D, Aessopos A, et al. $\beta$-thalassemia cardiomyopathy: history, present considerations, and future perspectives. Circ Heart Fail 2010;3:451-8.

3. Aessopos A, Farmakis D, Karagiorga M, et al. Cardiac involvement in thalassemia intermedia: a multicenter study. Blood 2001;97:3411-6.

4. Aessopos A, Farmakis D, Deftereos S, et al. Thalassemia heart disease: a comparative evaluation of thalassemia major and thalassemia intermedia. Chest 2005;127:1523-30.

5. Gladwin MT, Sachdev V, Jison ML, et al. Pulmonary hypertension as a risk factor for death in patients with sickle cell disease. $\mathrm{N}$ Engl $\mathrm{J}$ Med 2004;350:886-95.

6. Gladwin MT, Vichinsky E. Pulmonary complications of sickle cell disease. N Engl J Med 2008;359:2254-65.

7. Aessopos A, Farmakis D, Trompoukis C, et al. Cardiac involvement in sickle $\beta$-thalassemia. Ann Hematol 2009;88:557-64.

8. Grisaru D, Rachmilewitz EA, Mosseri M, et al. Cardiopulmonary assessment in $\beta$-thalassemia major. Chest 1990;98:1138-42.

9. Du ZD, Roguin N, Milgram E, Saab K, Koren A. Pulmonary hypertension in patients with thalassemia major. Am Heart J 1997;134:532-7.

10. Aessopos A, Farmakis D, Hatziliami A, et al. Cardiac status in welltreated patients with thalassemia major. Eur J Haematol 2004;73:359-66.

11. Simonneau G, Robbins IM, Beghetti M, et al. Updated clinical classification of pulmonary hypertension. J Am Coll Cardiol 2009;54:S43-54.

12. Galiè N, Hoeper MM, Humbert M, et al. Guidelines for the diagnosis and treatment of pulmonary hypertension: The Task Force for the Diagnosis and Treatment of Pulmonary Hypertension of the European Society of Cardiology (ESC) and the European Respiratory Society (ERS), endorsed by the International Society of Heart and Lung Transplantation (ISHLT). Eur Heart J 2009;30:2493-537.

13. Gladwin MT, Lancaster JR Jr, Freeman BA, Schechter AN. Nitric oxide's reactions with hemoglobin: a view through the SNO-storm. Nat Med 2003;9:496-500.

14. Aessopos A, Farmakis D, Tsironi M, et al. Endothelial function and arterial stiffness in sickle-thalassemia patients. Atherosclerosis 2007;191:427-32.

15. Aessopos A, Farmakis D, Loukopoulos D. Elastic tissue abnormalities resembling pseudoxanthoma elasticum in $\beta$ thalassemia and the sickling syndromes. Blood 2002;99:30-5.

16. Aessopos A, Samarkos M, Voskaridou E, et al. Arterial calcifications in $\beta$-thalassemia. Angiology 1998;49:137-43.

17. Tsomi K, Karagiorga-Lagana M, Fragodimitri C, Karabatsos F, Katsiki V. Arterial elastorrhexis: manifestation of a generalized connective tissue disorder in $\beta$-thalassaemia major. Eur $\mathrm{J}$ Haematol 1999;63:287-94.

18. Haque AK, Gokhale S, Rampy BA, Adegboyega P, Duarte A, Saldana MJ. Pulmonary hypertension in sickle cell hemoglobinopathy: a clinicopathologic study of 20 cases. Hum Pathol 2002;33:1037-43.

19. Farmakis D, Vesleme V, Papadogianni A, Tsaftaridis P, Kapralos P, Aessopos A. Aneurysmatic dilatation of ascending aorta in a patient with $\beta$-thalassemia and a pseudoxanthoma elasticum-like syndrome. Ann Hematol 2004;83:596-9.

20. Eldor A, Rachmilewitz EA. The hypercoagulable state in thalassemia. Blood 2002;99:36-43.

21. Aessopos A, Kati M, Farmakis D. Heart disease in thalassemia intermedia: a review of the underlying pathophysiology. Haematologica 2007;92:658-65.

22. Sonakul D, Fucharoen S. Pulmonary thromboembolism in thalassemic patients. Southeast Asian J Trop Med Public Health 1992;23:25-8.

23. Anthi A, Machado RF, Jison ML, et al. Hemodynamic and functional assessment of patients with sickle cell disease and pulmonary hypertension. Am J Respir Crit Care Med 2007;175:1272-9.

24. Lippman SM, Abergel RP, Ginzton LE, et al. Mitral valve prolapse in sickle cell disease: manifestation of a generalized connective tissue disorder. Am J Hematol 1985;19:1-12.

25. Kremastinos DT, Tiniakos G, Theodorakis GN, Katritsis DG, Toutouzas PK. Myocarditis in $\beta$-thalassemia major. A cause of heart failure. Circulation 1995;91:66-71.

26. Aessopos A, Farmakis D. Pulmonary hypertension in $\beta$-thalassemia. Ann N Y Acad Sci 2005;1054:342-9.

27. Barnett CF, Hsue PY, Machado RF. Pulmonary hypertension: an increasingly recognized complication of hereditary hemolytic anemias and HIV infection. JAMA 2008;299:324-31.

28. Derchi G, Forni GL, Formisano F, et al. Efficacy and safety of sildenafil in the treatment of severe pulmonary hypertension in patients with hemoglobinopathies. Haematologica 2005;90:452-8.

29. Machado RF, Martyr S, Kato GJ, et al. Sildenafil therapy in patients with sickle cell disease and pulmonary hypertension. Br J Haematol 2005;130:445-53.

30. Little JA, Hauser KP, Martyr SE, et al. Hematologic, biochemical, and cardiopulmonary effects of L-arginine supplementation or phosphodiesterase 5 inhibition in patients with sickle cell disease who are on hydroxyurea therapy. Eur J Haematol 2009;82:315-21.

31. Minniti CP, Machado RF, Coles WA, Sachdev V, Gladwin MT, Kato GJ. Endothelin receptor antagonists for pulmonary hypertension in adult patients with sickle cell disease. Br J Haematol 2009;147:737-43.

32. Barst RJ, Mubarak KK, Machado RF, et al.; on behalf of the ASSET study group*. Exercise capacity and haemodynamics in patients with sickle cell disease with pulmonary hypertension treated with bosentan: results of the ASSET studies. Br J Haematol 2010.

33. Taher AT, Musallam KM, Karimi M, et al. Overview on practices in thalassemia intermedia management aiming for lowering complication rates across a region of endemicity: the OPTIMAL CARE study. Blood 2010;115:1886-92.

34. Karimi M, Borzouee M, Mehrabani A, Cohan N. Echocardiographic finding in $\beta$-thalassemia intermedia and major: absence of pulmonary hypertension following hydroxyurea treatment in $\beta$-thalassemia intermedia. Eur J Haematol 2009;82:213-8.

35. Atichartakarn V, Chuncharunee S, Chandanamattha P, Likittanasombat K, Aryurachai K. Correction of hypercoagulability and amelioration of pulmonary arterial hypertension by chronic blood transfusion in an asplenic hemoglobin $\mathrm{E} / \beta$-thalassemia patient. Blood 2004;103:2844-6. 